\title{
PEMBERIAN CORE STABILITY EXERCISE UNTUK MENGURANGI NYERI DAN MENINGKATKAN AKTIVITAS FUNGSIONAL PADA KASUS SPONDYLOLISTHESIS LUMBAL
}

\author{
Kamilia Malihah Nur Salsabila ${ }^{1}$, Triana Karnadipa ${ }^{1}$ \\ ${ }^{1}$ Program Studi D3 Fisioperapi, Program Pendidikan Vokasi, Universitas Indonesia, Kota Depok, Indonesia \\ *Email korespondesi: malihahkamilia@gmail.com
}

\begin{abstract}
ABSTRAK
Spondylolisthesis merupakan suatu pergeseran ke depan satu korpus vertebra (vertebral body) jika dibandingkan dengan vertebra yang terletak dibawahnya (inferior). Hal ini menyebabkan dampak mekanis, radikuler, atau nyeri. Tujuan: Studi kasus ini bertujuan untuk mengevaluasi pengaruh intervensi fisioterapi core stability exercise pada pasien wanita berusia 63 tahun dengan diagnosis spondylolisthesis dalam mengurangi nyeri dan meningkatkan aktivitas fungsional pada sendi lumbal. Metode: Studi kasus tunggal dengan intervensi core stability exercise yang diberikan pada penelitian ini berupa posterior pelvic tilt exercise, bridging exercise, bird-dog exercise, dan wall squat exercise dilakukan 9 kali treatment selama 3 minggu. Nyeri dievaluasi dengan menggunakan visual analog scale (VAS) dan aktivitas fungsional dengan oswestry disability index (ODI). Hasil Temuan: Setelah dilakukan sembilan kali intervensi, terjadi penurunan nyeri pada gerak fleksi neck (2 poin), gerak fleksi trunk (1 poin), gerak fleksi hip bilateral (2 poin), nyeri tekan $m$. piriformis bilateral (1 poin), nyeri tekan $m$. hamstring bilateral (2 poin), nyeri tekan m. gastrocnemius bilateral (2 poin), dan nyeri tekan celah processus transversus vertebra L5(1 poin). Penurunan skor ODI menunjukkan penurunan disabilitas fungsional pasien sebanyak 9 poin. Kesimpulan: Berdasarkan hasil tersebut, dapat disimpulkan bahwa intervensi core stability exercise cukup efektif untuk mengurangi nyeri dan meningkatkan aktivitas fungsional pada pasien spondylolisthesis pada vertebra lumbal.
\end{abstract}

Kata Kunci: Aktivitas fungsional, Core stability exercise, Nyeri, dan Spondylolisthesis

\section{ABSTRACT}

Spondylolisthesis is a forward displacement of one vertebral body when compared to the vertebra below (inferior). This causes mechanical and radicular impact, and also pain. Objective: This case study aims to evaluate the effect of core stability exercise physiotherapy intervention on a 63-year-old female patient with a diagnosis of spondylolisthesis in reducing pain and increasing functional activity in the lumbar joints. Methods: A single case report, core stability exercise given in this study in the form of posterior pelvic tilt exercise, bridging exercise, bird-dog exercise, and wall squat exercise performed 9 treatments for 3 weeks. Pain was measured using visual analog scale (VAS) and functional activity was measured using oswestry disability index (ODI). Results: After nine times of interventions, there was a decrease in pain in neck flexion (2 points), trunk flexion (1 point), bilateral hip flexion (2 points), tenderness $m$. bilateral piriformis (1 point), tenderness $m$. bilateral hamstrings (2 points), tenderness $m$. Bilateral gastrocnemius (2 points), and L5 transverse process fissure tenderness (1 point). The decrease in the ODI score showed a decrease in the patient's functional disability by 9 points. Conclusion: Based on these results, it can be said that core stability exercises are quite effective in reducing pain and increasing functional activity in patients with spondylolisthesis in the lumbar spine.

Keywords: Core stability exercise, Functional activity, Spondylolisthesis, and Pain 


\section{PENDAHULUAN}

Spondylolisthesis didefinisikan sebagai translasi anterior satu segmen vertebra daripada vertebra lainnya. Dalam keadaan fisiologis normal, facet joint, diskus intervertebralis, struktur ligament anterior dan posterior, serta otot pembungkus mempertahankan kesejajaran vertebra (Gallagher et al., 2020). Spondylolisthesis merupakan salah satu penyebab patobiomekanikal dan patoanatomikal dari Low Back Pain (LBP) yang dapat bersifat degeneratif, iskemik, kongenital, traumatis, patologis dan iatrogenic (karena operasi dekompresi lumbal) (Mohammadimajd et al., 2020).

Spondylolisthesis diklasifikasikan oleh Meyerding menjadi 5 bagian yang digunakan untuk menentukan besarnya listhesis (Gallagher et al., 2020).
a. Grade I apabila pergeseran korpus 0-25\%
b. Grade II apabila pergeseran $25-50 \%$
c. Grade III apabila pergeseran 50-75\%
d. Grade IV apabila pergeseran $75-100 \%$
e. Grade V atau spondyloptosis didefinisikan dengan subluksasi lengkap dari vertebra superior pada vertebra inferior Spondylolisthesis juga diklasifikasikan berdasarkan penyebab terjadi pergeseran segmen tulang belakang, menurut klasifikasi Wiltse, yaitu displastik, isthmik, degeneratif, trauma, dan patologis (Duncan, 2019).

Translasi dan rotasi vertebra pada spondylolisthesis yang berlebihan menyebabkan abnormalitas sistem stabilitas tulang belakang (Suyasa, 2018). Ketidaksimetrisan facet joint menimbulkan instabilitas pada tulang belakang dan dapat memburuk karena penuaan. Spondylolisthesis dapat memberikan manifestasi sensasi nyeri karena terjadi kompresi diskus dan medulla spinalis pada susunan saraf tepi area tulang belakang (Chaerunnisa et al., 2019). Spondylolisthesis dapat disertai dan tidak disertai spondilosis yang menyebabkan radikulopati yang signifikan dan defisit neurologis progresif akibat kompresi akar saraf. Gangguan nyeri pada regio lumbal ini menyebabkan spasme otot paravertebra lumbal sehingga terjadi ketidakseimbangan antara core muscle dan otot paravertebra dalam mempertahankan trunk, sehingga menyebabkan penurunan mobilitas lumbal dan aktivitas fungsional tergangggu, seperti mengangkat, membungkuk, dan memutar badan (Chaerunnisa et al., 2019).

Core muscle termasuk dalam otot trunk yang memainkan peran penting dalam menjaga stabilitas segmental dan mengendalikan gerakan intervertebralis (Hsu et al., 2018). Beberapa peneliti melaporkan bahwa penurunan fungsi otot dapat mengubah tingkat pergerakan vertebra segmental. Oleh karena itu, latihan Otot-otot trunk melalui latihan spesifik (core stability exercise) diharapkan dapat meningkatkan gerakan intervertebralis dan menghasilkan kestabilan segmental yang lebih baik.

Core stability exercise merupakan teknik yang biasa digunakan fisioterapis untuk meningkatkan neuromuscular control serta koordinasi dan endurance dari otot trunk untuk menjaga stabilitas tulang belakang (Mohammadimajd et al., 2020). Penelitian yang dilakukan oleh Javadian et al. (2015) menunjukkan bahwa core stability exercise dapat meningkatkan stabilitas lumbal dengan faktor peningkatan fungsi otot lokal, aktivasi core muscle, dan peningkatan kontrol motorik lumbal pada pasien spondylolisthesis. Penelitian yang dilakukan oleh Javadian et al menunjukkan bahwa core stability exercise dapat meningkatkan stabilitas lumbal dengan faktor peningkatan fungsi otot lokal, aktivasi core muscle, dan peningkatan kontrol motorik lumbal pada pasien spondylolisthesis (Javadian et al., 2015). Penemuan ini didukung oleh Mohammadimajd et al. yang menunjukkan bahwa core stability exercise memiliki efek positif pada penurunan nyeri dan peningkatan kemampuan fungsional pada pasien spondylolisthesis karena latihan yang dilakukan tidak memprovokasi nyeri (Mohammadimajd et al., 2020).

Berdasarkan latar belakan diatas, penulis tertarik untuk mengevaluasi pengaruh pemberian core stability exercise untuk mengurangi nyeri dan meningkatkan aktivitas fungsional pada pasien dengan spondylolisthesis vertebra lumbal.

\section{METODE PENELITIAN}

Metodologi penelitian yang digunakan dalam penelitian ini adalah case report dengan resume kasus dan masalah klinis sebagai berikut:

\section{Kasus}


Wanita yang berusia 63 tahun, ibu rumah tangga, dengan diagnosis medik spondylolisthesis lumbal. Pada awal november 2017, orang sakit (OS) merasa nyeri dan kebas dipantat kanan ketika duduk terlalu lama. Saat itu OS hanya membiarkannya karena berpikir itu hanya pegal biasa dan akan hilang ketika istirahat. Semakin hari OS merasa nyeri dan kebas di pantat kanan bertambah ketika duduk selama 30 menit. Nyeri yang dirasakan adalah panas dan kesemutan. Nyeri mereda setelah OS mengistirahatkan tubuhnya dengan posisi terlentang. OS sering kali mencoba meraba dan mencubit pantat kanan namun OS tidak merasakan apapun. Pada 20 November 2017 memeriksakan diri ke RSUD Sukoharjo. Dari dokter umum kemudian OS dirujuk ke dokter orthopedi, dan dianjurkan melakukan rontgen. Dari hasil rontgen, dokter mengatakan bahwa OS mengalami pengapuran dan pegeseran tulang belakang sehingga menjepit saraf yang menimbulkan nyeri pada pantat kanan. Dokter memberi obat anti nyeri dan merujuk OS ke rehabilitasi medik untuk menjalani fisioterapi.

OS rutin ke fisioterapi selama 2 kali seminggu dari November 2017 sampai saat ini di RSUD Sukoharjo. Selama satu tahun pertama fisioterapi, OS diberi penanganan inframerah, TENS, dan latihan pada kaki seperti menjapit benda kecil menggunakan kedua kaki, menghitung kelerang dengan kaki kanan, dan memindahkan kain dengan menjapit menggunakan jari-jari kaki kanan. Selama dua tahun terakhir ini OS mengatakan hanya diberi penanganan inframerah dan TENS.

Saat ini OS merasakan nyeri menjalar dari pantat sampai kedua punggung kaki ketika duduk dan berdiri lama sekitar 30 menit dan berjalan sejauh 200 meter. Nyeri yang dirasakan membuat OS kesulitan melakukan pekerjaan rumah tangga seperti mencuci, menyapu, dan bersih-bersih. Selain itu OS juga kesulitan memindahkan atau mengangkat benda yang berat dan pergi ke masjid untuk salat berjamaah.

Pemeriksaan yang dilakukan pada tanggal 20 Maret 2021, penulis menemukan beberapa permasalahan yang terdapat pada pasien, yaitu pada full Range of Motion (ROM) ditemukan nyeri gerak fleksi neck, fleksi trunk, dan fleksi hip bilateral dan keterbatasan gerakan aktif (lateral fleksi dan rotasi) dan pasif (lateral fleksi) trunk bilateral, gerakan aktif (ekstensi, adduksi, dan endorotasi) hip bilateral, gerakan aktif (plantar fleksi dan inversi) ankle bilateral.

Pemeriksaan Manual Muscle Testing (MMT) ditemukan adanya kelemahan otot ( $m$. erector spine, $m$. quadratus lumborum bilateral, $m$. iliopsoas bilateral, $m$. gluteus maximus bilateral, m. gluteus medius bilateral, m. adductor bilateral, $m$. obturator externus bilateral, $m$. gluteus minimus bilateral, m. hamstring bilateral, $m$. quadriceps bilateral, m. gastrocnemius bilateral, $m$. tibialis anterior bilateral, $m$. pernoneus bilateral, dan $m$. tibialis posterior bilateral).

Pemeriksaan dengan palpasi ditemukan spasme pada $m$. upper trapezius, otot paravertebra lumbal, $m$. piriformis, m. gluteus maximus, $m$. hamstring, dan m. gastrocnemius bilateral, nyeri tekan $m$. piriformis, $m$. hamstring, dan $m$. gastrocnemius bilateral). Pemeriksaan keseimbangan dilakukan dengan Romberg test dan Single-legged stance test menunjukkan gangguan keseimbangan statis (berdiri). Terdapat gangguan pola jalan (antalgic gait sinistra), dan abnormal postur (sway back posture).

Pasien juga mengalami penurunan aktivitas fisik serta kemampuan fungsional seperti mampu duduk pada kursi tidak lebih dari 30 menit, berdiri tidak lebih dari 10 menit, berjalan sejauh 170 meter pada 6 Minutes Walking Test (6MWT), kesulitan membawa dan mengangkat benda berat, kesulitan melakukan pekerjaan rumah tangga, kesulitan beribadah di masjid, kesulitan bersosialisasi dengan komunitas ibu-ibu kampung, dan kesulitan bepergian. Selain itu pasien juga memiliki faktor penyakit penyerta yaitu osteoarthritis genu dextra sejak tahun 2020 .

\section{Intervensi}

Program fisioterapi yang dilakukan adalah Core stability exercise yang terdiri dari latihan posterior pelvic tilt exrcise, bridging exercise, bird-dog exercise, dan wall squat exercise. Intervensi ini diberikan untuk memperkuat dan meningkatkan stabilisasi core muscle dan otot lower extremity, sehingga dapat membantu mengurangi nyeri dan meningkatkan aktivitas fungsional pasien. Intervensi dilakukan sebanyak 9 kali dengan frekuensi 3 kali seminggu (3 set, dengan 10 kali repetisi dana hold 10 detik) dalam 


\section{Indonesian Journal of Physiotherapy}

Vol. 1, No. 2, Agustus 2021

3 minggu dari 16 April 2021 sampai dengan tanggal 6 Mei 2021.

Core stability exercise dilakukan secara bertahap pada pasien seperti untuk persiapan bridging exercise dilakukan aktivasi core muscle terlebih dahulu dengan mengangkat pantat ke atas sedikit dan ditahan selama 10 detik, kemudian pasien istirahat selama 5 detik dan dilanjutkan dengan mengangkat pantat lebih tinggi dari sebelumnya, dilakukan seperti itu sampai pasien mampu bridging dengan sempurna. Aktivasi otot juga dilakukan pada persiapan intervensi bird-dog exercise dan wall squat exercise.

\section{Instrumen Pengukuran}

Parameter yang digunakan untuk skala penilaian nyeri adalah Visual Analog Scale (VAS). Pemeriksaan ini menggunakan alat grafik visual untuk menentukan tingkat nyeri secara subyektif pada skala 0-10 (Kuenze \& Hart, 2018). Pasien diminta untuk memberikan skor dari 0 sampai 10 untuk intensitas nyeri yang dirasakan pasien pada waktu tertentu atau selama aktivitas. Skor 0 menunjukkan tidak terdapat gejala nyeri sama sekali dan 10 menunjukkan intensitas nyeri yang maksimal atau paling parah.
Oswestry disability index (ODI) atau dikenal juga oswestry low back pain disability questionnaire merupakan penilaian yang digunakan untuk mengukur kemampuan fungsional pasien sehari-hari (American Association of Orthopedic Surgeons (AAOS), n.d.). Tes ini dianggap sebagai "gold standard" dari parameter fungsional dari low back pain. Pada kuisioner ini di setiap pertanyaan terdapat 5 opsi dengan total 10 pertanyaan. Hasil dari tes ini berupa skor yang menunjukkan tingkat disabilitas pasien.

\section{HASIL}

Pada kasus ini terdapat problematik pasien berupa nyeri gerak fleksi neck, fleksi trunk, dan fleksi hip bilateral dan nyeri tekan $m$. piriformis, $m$. hamstring, dan $m$. gastrocnemius bilateral, studi dilakukan menggunakan parameter Visual Analog Scale (VAS). Hasil dari evaluasi nyeri dapat dilihat pada (Diagram 1).

Setelah dilakukan 9 kali terapi dengan 4 kali evaluasi didapatkan penurunan nyeri yang diukur dengan VAS dengan penurunan terbanyak yaitu 2 poin pada nyeri gerak fleksi neck, fleksi hip bilateral, dan nyeri tekan $m$. hamstring bilateral dan $m$. gastrocnemius bilateral.

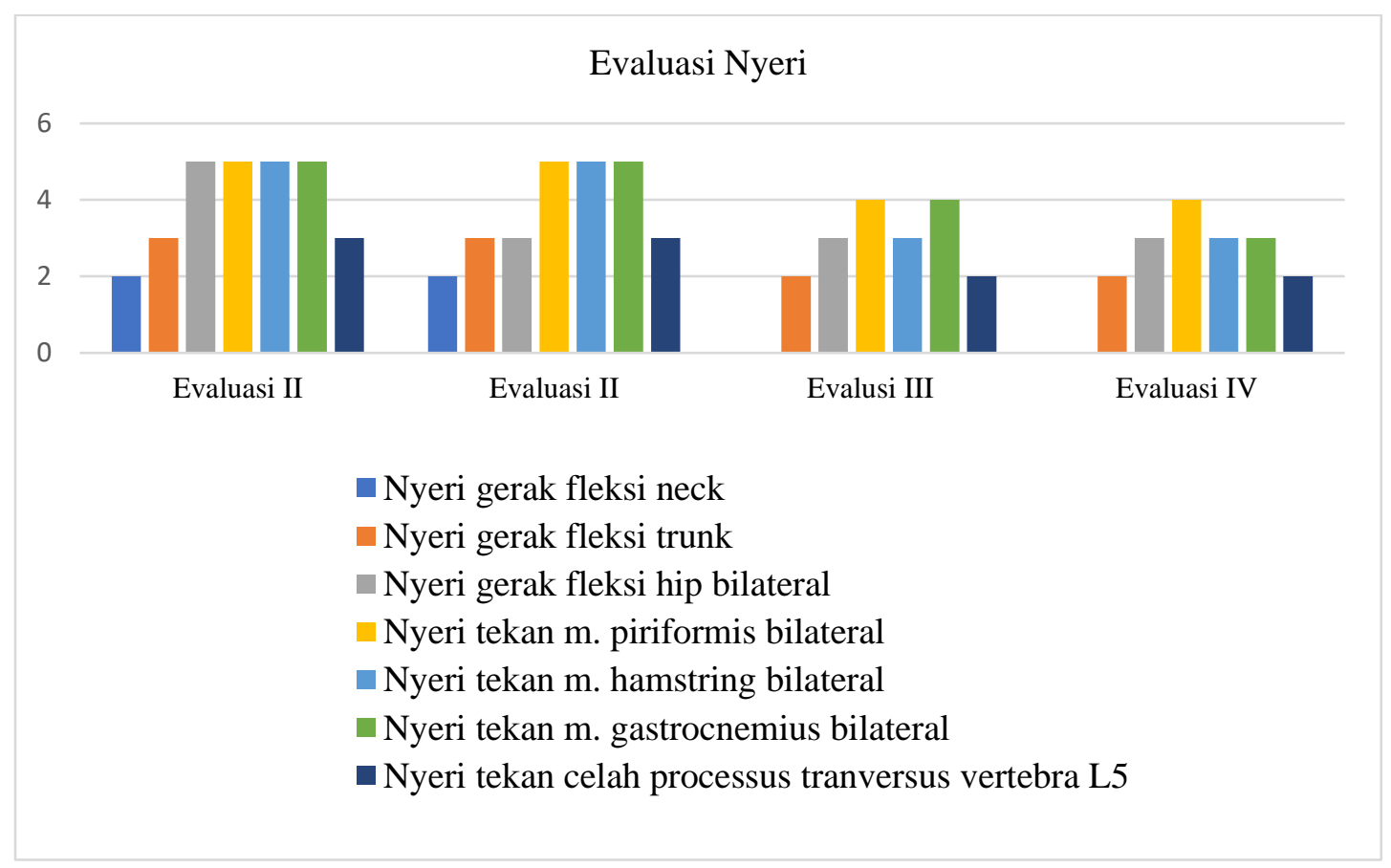

\section{Diagram 1 Evaluasi Nyeri}




\section{Indonesian Journal of Physiotherapy}

Vol. 1, No. 2, Agustus 2021

Perubahan kemampuan aktivitas fungsional pasien diukur dengan parameter Oswestry Disability Index (ODI). Hasil dari

evaluasi aktivitas fungsional dapat dilihat pada (Diagram 2).

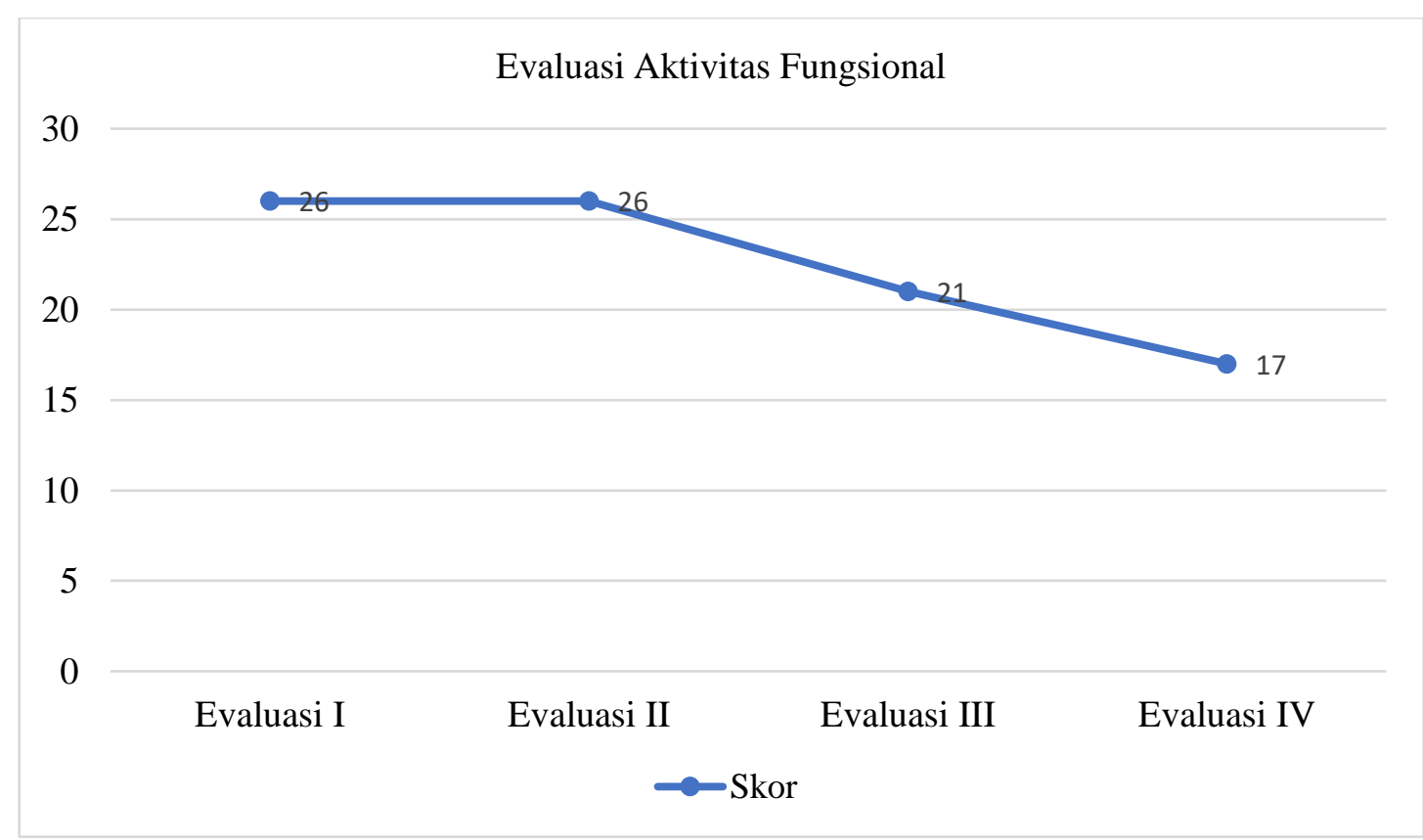

Diagram 2 Evaluasi aktivitas fungsional dengan parameter ODI

Berdasarkan diagram diatas dilakukan 9 kali terapi dengan 4 kali evaluasi didapatkan penurunan skor ODI yang menunjukkan penurunan tingkat disabilitas aktivitas fungsional pasien sebanyak 9 poin. Puncak penurunan ODI terjadi pada evaluasi ke-III sebanyak 5 poin.

Sebelum dilakukannya fisioterapi pasien mengeluhkan bahwa pasien kesulitan dalam beribadah ke masjid terutama saat salat tarawih di masjid pasien hanya dapat salat dengan duduk serta pasien kesulitan mengikuti kegiatan komunitas ibu-ibu kampung. Pada evaluasi ke-III pasien mengatakan setelah beberapa kali intervensi, pasien sudah dapat salat tarawih berjamaah di masjid dengan berdiri penuh dengan sedikit intensitas nyeri yang dirasakan. Pasien juga sudah dapat mengikuti pengajian dan berkumpul dengan ibu-ibu kampung.

\section{PEMBAHASAN}

Hasil pemberian intervensi core stability exercie didapatkan penurunan nilai VAS setelah 9 kali treatment, hal ini didukung oleh penelitian yang dilakukan oleh Narouei et al. dengan intervensi core stability exercise yang dilakukan dengan durasi 15 menit, 5 hari dalam seminggu, selama 4 minggu (Narouei et al., 2020). Pada penelitian ini menyatakan bahwa bridging exercise dan bird-dog exercise dapat mengurangi nyeri pada pasien LBP dengan meningkatkan kekuatan global muscle dan local muscle. Hal ini dibuktikan dengan meningkatnya maksimum sinyal electromyography (EMG) pada $m$. transversus abdominis, m. multifidus, dan $m$. gluteus maximus selama 4 minggu intervensi yang menujukkan meningkatnya kekuatan dari kontraksi otot. Core stability exercise ini merangsang reseptor sensorik dan motorik pada core muscle dan meningkatkan neuromuscular control dan stabilisasi tulang belakang. Core stability exercise mengaktivasi otot trunk dan hip selama kontraksi isometrik, yang menyebabkan hipertrofi dan peningkatan kualitas kontraksi $m$. transversus abdominis, m. multifidus, dan $m$. gluteus maximus.

Studi ini juga menggunakan bridging exercise dan bird-dog exercise seperti dalam Narouei et al. (Narouei et al., 2020). Sebelum diberikan core stability exercise penulis memberikan intervensi terapi modalitas berupa 
infrared dan TENS dan terapi latihan berupa upper trapezius stretch, stretching knee-to-chest, gluteal-piriformis stretch, hamstring stretch, dan gastrocnemius stretch dengan tujuan mengurangi nyeri dan mengurangi spasme otot sebagai persiapan pasien untuk melakukan core stability exercise (Jung et al., 2020).

Intervensi squat exercise seperti dalam penelitian Mohammadimajd et al. yang dilakukan dengan media dinding sebagai fiksasi posterior badan pasien (wall squat exercise) (Mohammadimajd et al., 2020). Pasien memiliki abnormal postur berupa forward head, protraksi shoulder, dan hiperlordosis lumbal, sehingga memerlukan koreksi postur. Pada latihan ini pasien diminta menempelkan posterior lumbal, bahu, sampai dengan kepala dan perlahan menekuk kedua lutut. Latihan ini digunakan untuk meningkatkan kekuatan lower extremity serta koreksi postur, sehingga dapat menurunkan nyeri. $m$. gluteus maximus dan $m$. hamstring adalah otot aktif hip yang utama selama squat (Deniz \& Ulas, 2020).

Pemberian posterior pelvic tilt exercise terhadap pasien spondylolisthesis juga berperan dalam menurunkan nyeri seperti penelitian Salam et al. (Salam et al., 2020). Intervensi dilakukan 3 kali dalam semingu selama 4 minggu dengan durasi setiap sesi 30 menit menghasilkan penurunan nyeri menjalar pada tungkai posterior. Posterior pelvic tilt exercise berfungsi untuk mengurangi hiperlordosis pada vertebra lumbal, mengurangi kompresi saraf, dan meningkatkan kekuatan otot lumbal sehingga terjadi penurunan nyeri. Latihan ini perlahan akan memperbaiki lordosis pada vertebra lumbal dan merilekskan otot-otot pada punggung bawah yang menurunkan rasa nyeri.

Intervensi posterior pelvic tilt exercise juga dilakukan dalam penelitian penulis karena pasien memiliki kondisi hiperlordosis lumbal dengan bentuk postur swayback. Latihan ini dilakukan dengan supine position dengan kedua knee dan hip ditekuk, tangan fisioterapis berada dibawah lumbal pasien agar pasien lebih mudah untuk mengontraksikan otot abdominal dan memberi tekanan ke tangan fisioterapis. Pelvic tilt exercise bekerja dengan mengaktivasi core muscle intrinsik dan minimal kontraksi pada punggung bawah. Hal ini didukung penelitian oleh (Minicozzi et al., 2016) yang mendapatkan bahwa kinerja dari pelvic tilt exercise melibatkan beberapa derajat fleksi vertebra lumbal dengan "flattening" atau pengurangan lordosis lumbal, gerakan yang dilakukan secara sadar, sehingga intervensi ini juga berfungsi untuk memperbaiki abnormal postur.

Hasil pada penelitian ini dimana terdapat penurunan skor ODI sebesar 9 poin pada evaluasi keempat didukung oleh Penelitian yang dilakukan Mohammadimajd et al (2020). Studi menemukan terjadi penurunan skor ODI dari rata-rata awal 47,38 menjadi 30,37 pada 13 pasien spondylolisthesis setelah 2 kali seminggu, selama 8 minggu, setiap exercise di-hold 5-10 detik dengan 10 kali pengulangan setiap sesi. Penurunan skor ini menunjukkan penurunan disabilitas fungsional pada pasien. Peningkatan aktivitas fungsional pasien berhubungan dengan efek penurunan nyeri yang terjadi setelah intervensi core stability exercise yang telah dijelaskan sebelumnya. Intensitas nyeri sangat mempengaruhi aktivitas sehari-hari pasien, jika nyeri semakin memburuk maka akan semakin banyak aktivitas sehari-hari yang terhambat karena timbulnya nyeri. Begitu juga sebaliknya, ketika intensitas nyeri pasien berkurang, pasien akan lebih mudah melakukan aktivitas sehari-hari tanpa terganggu nyeri atau dengan keluhan minimal.

Penurunan nyeri menyebabkan pasien mampu melakukan salat tarawih berjamaah dengan berdiri penuh, mengikuti pengajian, dan berkumpul dengan ibu-ibu kampung. Adanya peningkatan kegiatan ini menunjukkan meningkatkatnya aktivitas fungsional pasien.

Limitasi pada penulisan artikel ini adalah penulis tidak memberikan intervensi strengthening exercise untuk lower extremity dan balance exercise sehingga tidak terdapat peningkatan pada keseimbangan pasien. Penulis tidak memberikan stretching untuk otot lateral fleksor dan rotator trunk, sehingga spasme pada otot paralumbal tidak turun secara efektif. Pasien tidak rutin melakukan home program yang penulis berikan, akan lebih efektif jika pasien rutin melakukannya. Hasil fisioterapi mungkin akan lebih signifikan jika dilakukan dalam periode waktu yang lebih lama. 


\section{KESIMPULAN}

Pasien berisinial Ny. S usia 63 tahun dengan diagnosis spondylolisthesis lumbal. Dari berbagai problematik fisioterapi yang ditemukan, dilakukannya intervensi sebanyak 9 kali fisioterapi berupa core stability exercise dengan 4 kali evaluasi dengan hasil:

1. Nyeri gerak terjadi penurunan rata-rata 2 poin VAS pada gerak fleksi trunk fleksi hip bilateral, serta sudah tidak terdapat nyeri gerak fleksi neck.

2. Kekuatan otot terjadi peningkatan ratarata 1 poin MMT pada $m$. erector spine, $m$. quadratus lumborum bilateral, $m$. iliopsoas, m. gluteus maximus bilateral, m. adductor bilateral.

3. Nyeri tekan terjadi penurunan rata-rata 2 poin VAS pada $m$. piriformis bilateral, $m$. hamstring bilateral, $m$. gastrocnemius bilateral, celah processus transversus L5.

4. Peningkatan kemampuan aktivitas fungsional pasien dilihat dari penurunan 9 skor ODI.

Akan tetapi, tidak terdapat perubahan signifikan pada spasme otot dan tidak terdapat peningkatan keseimbangan statis (berdiri).

\section{DAFTAR PUSTAKA}

American Association of Orthopedic Surgeons (AAOS). (n.d.). Scoring the Oswestry Disability Index.

Chaerunnisa, A., Latief, S., \& Karsa, N. S. (2019). Hubungan Derajat Spondylolisthesis Dengan Nyeri Pasien Low Back Pain Rumah Sakit Ibnu Sina Makassar. Green Medical Journal, 1(1), 77-86. https://doi.org/10.33096/gmj.v1i1.22

Deniz, E., \& Ulas, Y. H. (2020). Evaluation of muscle activities during different squat variations using electromyography signals. Advances in Intelligent Systems and Computing, 1095 AISC(May), 859-865. https://doi.org/10.1007/978-3-03035249-3_114
Duncan, L. T. (2019). Advances in Health Disease (Vol. 17).

Gallagher, B., Moatz, B., \& Tortolani, P. J. (2020). Classifications in Spondylolisthesis. Seminars in Spine Surgery, 32(3), 1-7. https://doi.org/10.1016/j.semss.2020.10 0802

Hsu, S.-L., Oda, H., Shirahata, S., Watanabe, M., \& Sasaki, M. (2018). Effects of core strength training on core stability. The Journal of Physical Therapy Science, $30(8)$ 1014-1018. http://search.ebscohost.com/login.aspx? direct $=$ true $\& d b=j l h \& A N=105485717 \&$ lang=es\&site $=$ ehost-live

Javadian, Y., Akbari, M., Talebi, G., Taghipour-Darzi, $\quad$ M., \& Janmohammadi, N. (2015). Influence of core stability exercise on lumbar vertebral instability in patients presented with chronic low back pain: A randomized clinical trial. Caspian Journal of Internal Medicine, 6(2), 98102.

Jung, J. Y., Heo, M., \& Kim, J. J. (2020). Effects of a personalized exercise rehabilitation device on dynamic postural balance for scoliotic patients: A feasibility study. Electronics (Switzerland), 9(12), 1-14. https://doi.org/10.3390/electronics9122 100

Kuenze, C. M., \& Hart, J. (2018). Sports Knee Rating Systems and Related Statistics (Sixth Edit). Elsevier Inc.

Minicozzi, S. J., Russell, B. S., Ray, K. J., Struebing, A. Y., \& Owens, E. F. (2016). Low Back Pain Response to Pelvic Tilt Position: An Observational Study of Chiropractic Patients. Journal of Chiropractic Medicine, 15(1), 27-34. https://doi.org/10.1016/j.jcm.2016.02.0 09

Mohammadimajd, E., Lotfinia, I., 


\section{Indonesian Journal of Physiotherapy}

Vol. 1, No. 2, Agustus 2021

Salahzadeh, Z., Aghazadeh, N., Noras, P., Ghaderi, F., Poureisa, M., Sarbakhsh, P., \& Choopani, R. (2020). Comparison of lumbar segmental stabilization and general exercises on clinical and radiologic criteria in gradeI spondylolisthesis patients: A doubleblind randomized controlled trial. Physiotherapy Research International, 25(3), $1-10$. https://doi.org/10.1002/pri.1843

Narouei, S., Barati, A. hossein, Akuzawa, H., Talebian, S., Ghiasi, F., Akbari, A., \& Alizadeh, M. hossein. (2020). Effects of core stabilization exercises on thickness and activity of trunk and hip muscles in subjects with nonspecific chronic low back pain. Journal of Bodywork and Movement Therapies, 24(4), 138-146. https://doi.org/10.1016/j.jbmt.2020.06. 026

Salam, D. A. A. El, Fayez, E. S., Ahmed, S. M., \& Khalifa, H. A. (2020). Effect of L4 Mobilization and Posterior Pelvic Tilting Exercise on Sciatica in Patients with Spondylolisthesis. The Medical Journal of Cairo University, 88(12), 2045-2050.

https://doi.org/10.21608/mjcu.2020.125 148

Suyasa, I. K. (2018). Diagnosis dan Tata Laksana Penyakit Degenerasi Lumbal. In Udayana University Press. 